\title{
INFLUENCE OF THERMOPLASTIC PROCESSING PARAMETERS ON THEIR INTERNAL TEMPERATURE
}

\author{
F. A. R. Campos, \\ and L. R. R. da Silva \\ Federal University of Uberlandia, School of \\ Mechanical Engineering, Av. João Naves de \\ Ávila, 2121, Bloco 1M, 38400-902, \\ Uberlândia, MG, Brazil. \\ filipin_anjos@hotmail.com \\ leorrs@ufu.br \\ Received: Jul 26, 2021 \\ Revised: Aug 06, 2021 \\ Accepted: Aug 08, 2021

\section{ABSTRACT} \\ With technological advances, polymers are increasingly used to manufacture \\ various components that were previously exclusively manufactured with \\ metals. One of the significant challenges in polymer processing is its \\ relatively low thermal resistance, since relatively small temperature \\ variations, especially when compared to metals and ceramics, lead to \\ significant changes in material properties and in the final component \\ geometry. This paper investigated how the internal temperature of polymers, \\ subjected to an intermittent particulate jet deposition process in conjunction \\ with a continuous flow of hot air, is affected by variation in surface \\ roughness, polymer type, and air pressure. As the main result, low efficiency \\ in heat transfer was caused by the combination of the convective nature of \\ the heat exchange with the low thermal conductivity of the polymers. The \\ variables with the most significant influence on the process were the \\ intermittence and pressure of the particulate jet. \\ Keywords: thermocouples, Arduino, thermoplastics, convection
}

\section{INTRODUCTION}

Polymers have been gaining more and more attention since the 20 th century due to their versatility and low manufacturing cost. They are made up of high molecular weight molecules, usually containing carbon, oxygen, and/or nitrogen in their molecular chains. Although they constitute a vast set of materials, they can be classified as elastomers, thermoplastics, and thermosets, according to the behavior of their macromolecules with temperature changes (Osswald et al., 2006). Thermoplastics have uncrossed molecules such that they flow viscously when heated but solidify as they cool. They have reasonable resistance at room temperature as solids and do not require much energy when processed by molding, finding several applications in packaging, transport, and even construction, since many thermoplastics have a tensile impact and even heat resistance in specific ranges.

Although polymers work well below their melting temperature in most applications, they are often heated in the manufacturing process to facilitate moldability and incorporate fillers and pigments. Engineers need to know the temperature range that the polymer experiences in these cases, affecting the process efficiency and final material characteristics. The first factor is because heating the material consumes energy but generally reduces the forces involved and speeds up reactions and mixing with additives. The second is related to thermoplastics' different mechanical and physical properties, depending on the cooling speed.

Temperature measurement and monitoring in these scenarios are accomplished in many ways, while thermocouples are some of the most appropriate choices. They are cheap, simple, robust, and withstand a wide range of temperatures (Oliveira et al., 2020). However, they cannot operate independently and need a system that converts their electrical voltage signals into digital data, calculates the corresponding temperature according to the voltage values, and shows the information to the user (Vasconcelos Neto et al., 2018). In line with the characteristics of simplicity, low cost, and robustness, Arduino $\AA$ compatible hardware and software were used in this work to acquire temperature data for a manufacturing process where the polymer experiences constant heating by hot air while being reached by an intermittent flow of compressed air at room temperature mixed with fine ceramic particulates.

The dynamics of these interactions cause the material surface to be constantly heated and cooled in short cycles, around temperatures high enough to change the bulk properties of the part. Although these cycles can cause instantaneous temperature variations on most external polymer surfaces, the internal regions will not undergo large oscillations due to attenuation due to the material's thermal conductivity and specific heat capacity.

In this work, the influence of substrate surface roughness, polymer type, compressed air 
pressure, and particulate mixed in this air was investigated concerning the polymer's internal temperature, developed at $1 \mathrm{~mm}$ from its surface. An acquisition system with type $\mathrm{K}$ thermocouples and Arduino board was used for data acquisition. The results show that the acquisition system is suitable for monitoring the material temperature during the process and indicate the dependence of this output variable on the established input parameters. The applied technique helps regulate the manufacturing process and can be used to feed future process temperature control algorithms.

\section{METHODOLOGY}

The temperature variation of polyamide and polycarbonate subjected to a continuous flow of hot air concomitant with an intermittent flow of compressed air at room temperature and mixed with ceramic particles was studied in order to assess the influence of process parameters on internal temperatures measured just below the surface reached by the air flows.

For this, type $\mathrm{K}$ thermocouples were used, whose wires are made of nickel-chromium and nickelaluminum alloys. They can be used from $-200^{\circ} \mathrm{C}$ to $1250^{\circ} \mathrm{C}$ as long as the wire coatings do not degrade (Omega Engineering, 2015). A MAX31855 module compatible with Arduino ${ }^{\circledR}$ was used, a built-in thermistor to automatically compensate for the cold junction temperature. The 14-bit module reads and converts analog signals into digital data and sends them to the ATMEGA 2560 microcontroller via SPI communication, where the temperature is calculated with a resolution of $0.25^{\circ} \mathrm{C}$. Their combination produces a sensitivity of about $41 \mu \mathrm{V} /{ }^{\circ} \mathrm{C}$, and its maximum error varies between $\pm 2{ }^{\circ} \mathrm{C}$ and $\pm 6^{\circ} \mathrm{C}$, depending on the temperature range being measured (Maxim Integrated, 2015). Compressed air line pressure was also recorded using a TMOEC piezoelectric pressure transducer. With an operating range from 0 to 12 bar, this sensor sends corresponding signals from $0.5 \mathrm{~V}$ to $4.5 \mathrm{~V}$ to the microcontroller, which calculates and records the pressure values with an accuracy of $1.5 \%$.

A Bosch GHG630 heat blower with up to $2000 \mathrm{~W}$ and temperature regulation via electronic thermostat was also used. The hot air temperature was set at $500{ }^{\circ} \mathrm{C}$ at the nozzle outlet and constantly reached the sample. Due to dispersion after the nozzle, the hot air reaches the surface of the parts already at a reduced temperature, around $370{ }^{\circ} \mathrm{C}$, measured sporadically by another thermocouple external to the sample. The pressure of the compressed air line was adjusted in the filter regulator, and the compressed air was directed to the sample by a blasting gun. Compressed air was released cyclically in pulses of 1 $\mathrm{s}$ and interruption for 3 or $5 \mathrm{~s}$, automatically opened and closed at regular times by a solenoid valve activated by the microcontroller. When open, the compressed air jet displaces the slightest hot airflow from the blower, absorbing heat from the sample.

The thermocouple, module, pressure transducer, and microcontroller were connected through a breadboard. The Arduino was connected to a laptop via a USB cable to record data to a text file at a rate of $5 \mathrm{~Hz}$. A bench was set up to move the samples along a $95 \mathrm{~mm}$ path with a constant speed of almost 3 $\mathrm{mm} / \mathrm{s}$, as shown in Fig. 1. When reaching the end of the stroke, the direction is automatically reversed, moving the parts back and forth cycles while the blower and gun are kept fixed.

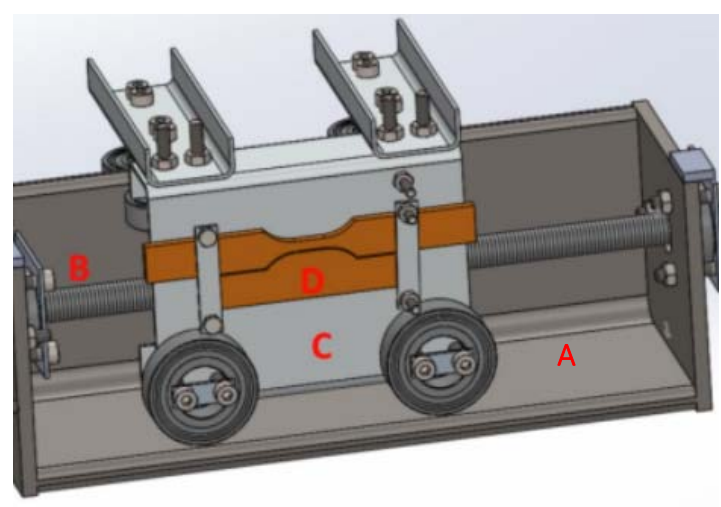

Figure 1. Track (A) and spindle (B) for moving the sample (D) attached to the support (C).

Figure 2 shows the thermocouple fixation scheme to the sample with epoxy resin. Since this device measures contact temperature, it is imperative to position it equally during all experiments. In this configuration, they were inserted through a blind hole drilled behind the samples and measure the sample temperature $1 \mathrm{~mm}$ below the surface reached by the hot air. Meanwhile, the other side of the polymer piece rests on a stainless steel support. The samples were cut from $3 \mathrm{~mm}$ plates in the shape of a $20 \mathrm{~mm} \times 70 \mathrm{~mm}$ parallelepiped.

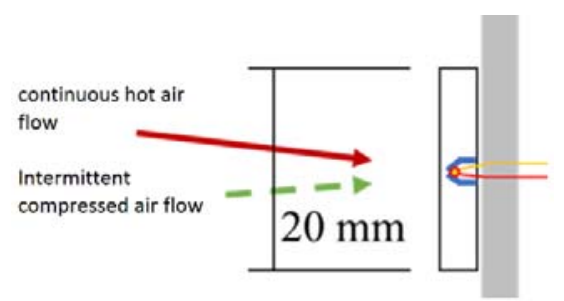

Figure 2. Positioning the thermocouple hot joint (yellow and red wires) in the sample's blind hole.

A $2^{6-3}$ fractional factorial design was used to evaluate the maximum (TintMax) and average (TintAvg) internal temperatures obtained by varying the type of polymer, composition and amount of particulates, the surface roughness of the samples, total time of the process, pressure, and intermittency of compressed air, as shown in Tab. 1. The particulates used were pure aluminum oxide (alumina) \#600 grain and a mixture of alumina with titanium dioxide 
(titania), whose submicrometric grains are used as pigment filler in white paints. The surfaces of the samples were previously conditioned by sanding to obtain a uniform roughness, measured by the parameter Ra.

Table 1. Input variables: (A) polymer type; (B) type and amount of particulate; (C) pressure and (D) compressed air intermittency; (E) total process time and (F) average Ra of the sanded surfaces.

\begin{tabular}{c|c|c|c|c|c|c|}
\hline trial & A & B & C & D & E & F \\
\hline 1 & -1 & 1 & -1 & 1 & 1 & -1 \\
\hline 2 & -1 & 1 & -1 & -1 & -1 & 1 \\
\hline 3 & -1 & -1 & 1 & -1 & 1 & -1 \\
\hline 4 & -1 & -1 & 1 & 1 & -1 & 1 \\
\hline 5 & 1 & -1 & -1 & 1 & -1 & -1 \\
\hline 6 & 1 & -1 & -1 & -1 & 1 & 1 \\
\hline 7 & 1 & 1 & 1 & -1 & -1 & -1 \\
\hline 8 & 1 & 1 & 1 & 1 & 1 & 1 \\
\hline \multirow{2}{*}{-1} & PC & $100 \%$ & 3 & $1 / 5$ & $07: 00$ & 6,25 \\
& & alumina & bar & s & min & $\mu \mathrm{m}$ \\
\hline \multirow{2}{*}{1} & Ny & $80 \%$ alumina + & 5 & $1 / 3$ & $04: 40$ & 3,13 \\
& & $20 \%$ titania & bar & s & min & $\mu \mathrm{m}$ \\
\hline
\end{tabular}

\section{RESULTS}

Every measurement system has errors and therefore requires not only calibration but also measurement of its uncertainty. These procedures were performed for the Arduino measurement system and K-type thermocouples in the works by Campos et al. $(2020 ; 2021)$, for which an expanded uncertainty of $\pm 2.75{ }^{\circ} \mathrm{C}$ was obtained with $\mathrm{K}=2,78$ and $95 \%$ confidence interval. Although K-type thermocouples have excellent linearity in the 0 to $600{ }^{\circ} \mathrm{C}$ range (Omega Engineering, 2015), as the uncertainty has been estimated for readings in the 30 to $100{ }^{\circ} \mathrm{C}$ range, it is expected that they may be somewhat larger for measurements temperatures in the range of 100 to 200 ${ }^{\circ} \mathrm{C}$ that develop inside the studied polymers.

The temperatures obtained in the 8 experiments are shown in Fig. 3. First, it is noted that TintMax is always more than $30{ }^{\circ} \mathrm{C}$ above TintAvg, with a more significant difference of $38.41{ }^{\circ} \mathrm{C}$ in test 6 and less than $29.14^{\circ} \mathrm{C}$ in test 4 , making TintAvg always around 20 to $30 \%$ smaller than TinMax. Another highlight is the relationship with the maximum hot air temperature at the exit of the heat blower nozzle, set at $500{ }^{\circ} \mathrm{C}$. The maximum internal temperatures are between 23 and $30 \%$ of this value, while the averages are between 17 and $24 \%$. However, the hot air disperses after the nozzle and reaches the surface of the polymers at a reduced temperature of around $370^{\circ} \mathrm{C}$, for which TintMax is between 39 and $47 \%$, while TintMed is between 29 and $38 \%$.

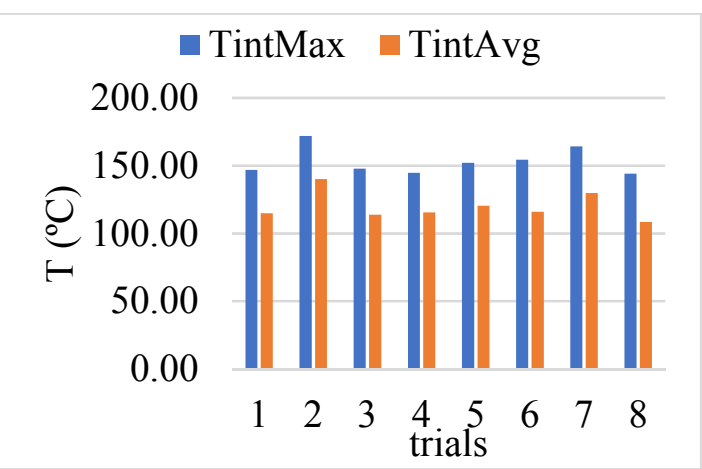

Figure 3. Maximum and average internal temperature developed in the sample in each test, varying the processing conditions.

Although these values are not sufficient to calculate the thermal efficiency of the process or the amount of heat transferred, these ranges give a general idea of the relationship between the temperature of the hot air and the temperatures developed below the surface of polycarbonate and polyamide. The maximum temperature is not even half that of the hot air, indicating a low efficiency in heat transmission.

In fact, the convection mechanism that governs this phenomenon is a form of conduction through the boundary layer (Bergman et al., 2011), as represented in Fig. 4. In the studied process, despite the Prandtl number $(\mathrm{Pr}=$ diffusivity ratio inertial and thermal fluid) close to 0.7 for atmospheric air at 370 ${ }^{\circ} \mathrm{C}$ favor heat diffusion beyond the velocity boundary layer (Yunus et al., 2020), the small sample area and low blower air velocity make so that the Reynolds number $(\mathrm{Re}=$ ratio of inertial to viscous forces in a fluid) is low and the flow is more likely to be laminar. Under these conditions, due to the low thermal conductivity of air (k) and the greater dependence of the Nusselt number $(\mathrm{Nu}=$ ratio between convection and conduction in a fluid) concerning Re than to $\mathrm{Pr}$, as suggested by the empirical relation of Eq. (1) for a flat plate of length $\mathrm{L}$, the general convection coefficient (h) is low (Bahrami, 2021). Furthermore, the transfer rate significantly decreases as the polymer temperature rises to TintMax, highlighting the limitation in polymer heating.

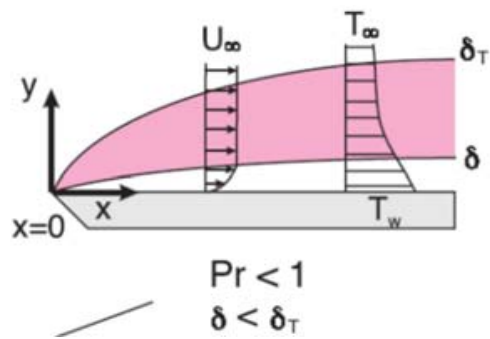

Figure 4. Boundary layers for temperature $(\delta \mathrm{T})$ and velocity $(\delta)$ in conditions that result in a Prandtl number greater than 1 , such as low-density fluid flows and thermal conductivity (Bahrami, 2021). 


$$
\mathrm{Nu}=\frac{\mathrm{hL}}{\mathrm{k}}=0,664 \operatorname{Re}_{\mathrm{L}}^{1 / 2} \operatorname{Pr}^{1 / 3}
$$

Another factor contributing to the limited heat transfer at these interfaces is the low thermal conductivity of the polymers used, in the range of 0.2 to $0.3 \mathrm{~W} / \mathrm{mK}$ for temperatures from 0 to $150{ }^{\circ} \mathrm{C}$ (Osswald et al., 2006 ). When solving Eq. (2) for heat diffusion in the thermoplastic solid, smaller values of $\mathrm{k}$ mean a profile $\mathrm{T}(\mathrm{x}, \mathrm{t})$ less inclined than the one in Fig. 5, whose smaller derivatives also reflect the reduction of $h$.

$$
-\mathrm{k} \frac{\mathrm{dT}(0, \mathrm{t})}{\mathrm{dx}}=\mathrm{h}\left[\mathrm{T}_{\infty, 1}-\mathrm{T}(0, \mathrm{t})\right]
$$

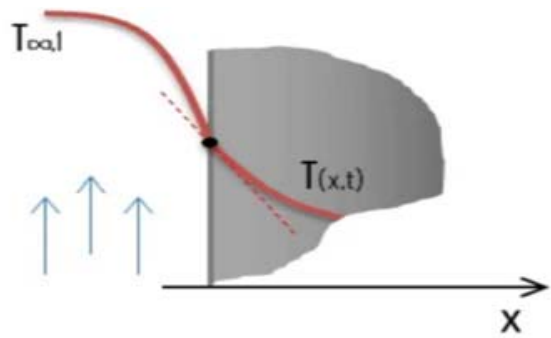

Figure 5. The temperature profile of the solid during convection (Bahrami, 2021).

The influences of the input variables on the internal temperature of the polymers are more evident in Fig. 6 to Fig. 16, according to the weighted averages resulting from the analysis of variance (ANOVA). For the maximum internal temperature (TintMax), it can be seen, for example, that the smallest intermittence of a jet of compressed air every four seconds led to a decrease in the TintMax, with average values going from $160{ }^{\circ} \mathrm{C}$ to $148{ }^{\circ} \mathrm{C}$. This can be easily explained thanks to the more significant cooling of the part by the cold air in this condition. Effectively, the different levels of this input variable mean that the heating flow during the process went from $86.3 \%$ to $80 \%$, and caused a temperature drop of $12{ }^{\circ} \mathrm{C}$ under these conditions, making this factor the most significant for the temperature experienced by the polymer.

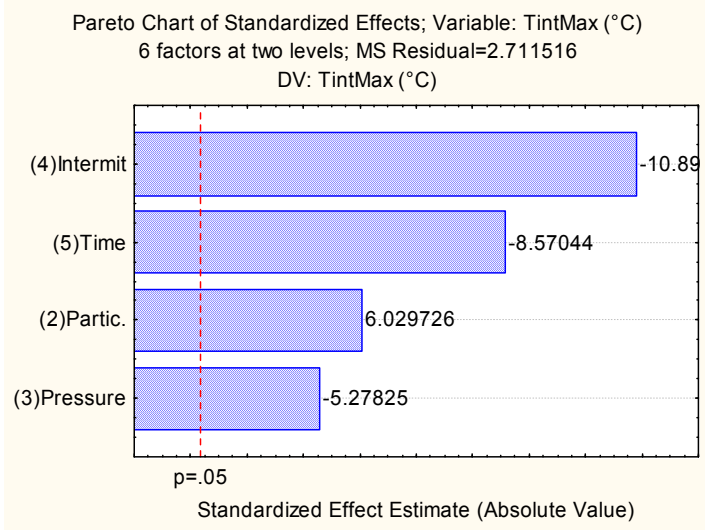

Figure 6. Pareto plot for significant input variables in TintMax, according to Anova.

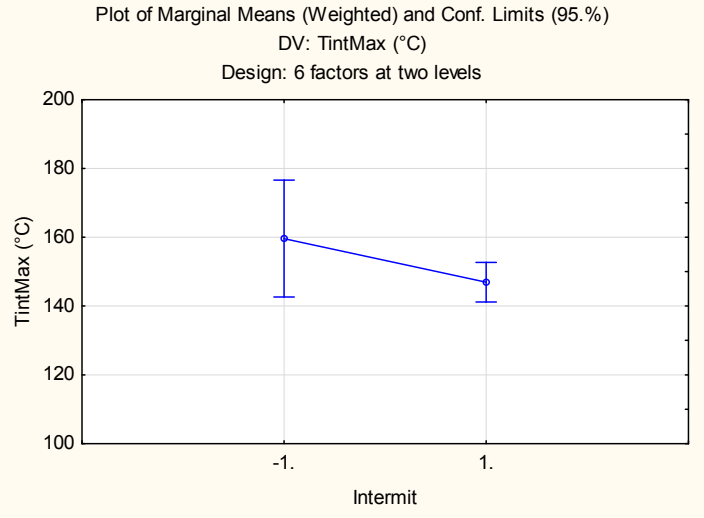

Figure 7. Average effect of intermittency levels $(-1 \equiv 1 / 5 \mathrm{~s}$; $1 \equiv 1 / 3 \mathrm{~s})$ on TintMax according to Anova.

The total processing time factor, on the other hand, caused a drop from approximately $160^{\circ} \mathrm{C}$ to 150 ${ }^{\circ} \mathrm{C}$ when it decreased from $420 \mathrm{~s}$ to $280 \mathrm{~s}$. This means that a $33.3 \%$ reduction in total time caused a $10{ }^{\circ} \mathrm{C}$ drop in the maximum temperature of the samples, making this variable the second most significant, as can be seen in the Pareto graph in Fig. 6.

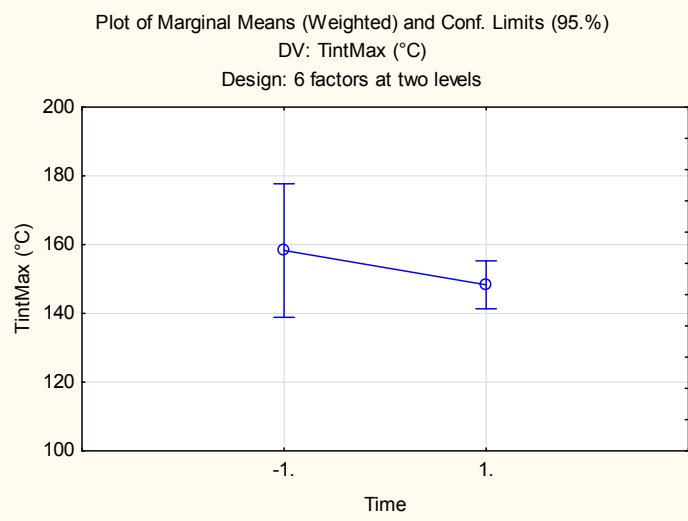

Figure 8. Average effect of time levels $(-1 \equiv 7 \mathrm{~min}$; $1 \equiv 4 \min 40 \mathrm{~s}$ ) in TintMax according to Anova.

The type and volumetric flow of ceramic particles were also significant for the material's heat exchange with hot air. As can be seen in Fig. 9, the temperature dropped from $158^{\circ} \mathrm{C}$ to $150^{\circ} \mathrm{C}$ when only pure alumina was used, whose average flow of $6 \mathrm{~mL}$ per second of compressed air is almost three times greater than the $2.1 \mathrm{~mL}$ per second resulting from the mixture of alumina and titania. Two factors can explain this behavior. First, it may be due to more significant heat loss from the heated sample when the particulate is released onto its surface. Thus, as the airflow is the same in both situations, the heat transfer from polymers to the particulate would be greater than for cold air, as the greater thermal capacity of the particulate would steal more heat from the substrate and reduce its internal temperature. The other possibility is that a portion of the ceramic particulate remains adhered to the surface and creates a thermal 
barrier, which would decrease the heat flux from the external hot air passing through the surface to the internal regions of the polycarbonate and polyamide. The lowest maximum temperature obtained in these cases is likely the result of these two factors together, although it is not possible to say which one is predominant.

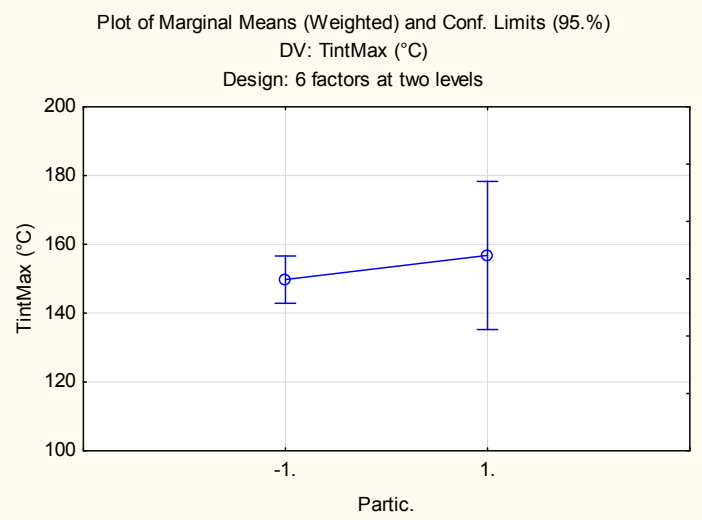

Figure 9. Average particulate effect $(-1 \equiv 100 \%$ alumina; $1 \equiv 80 \%$ alumina $+20 \%$ titania) in TintMax according to Anova.

Finally, the highest pressure also caused a decrease in the maximum internal temperature, with the smallest effect among all the variables evaluated. The average drop from $158{ }^{\circ} \mathrm{C}$ to $151^{\circ} \mathrm{C}$ was obtained using a pressure of 5 bar, $66.7 \%$ higher than the pressure of 3 bar. This phenomenon is due to the greater flow of cold air in this condition, which steals more heat due to the effect of greater thermal capacity. In addition, for higher pressures, compressed air impacts the part with greater speed, which increases the convection coefficient and accelerates the heat loss from the samples to the cold air.

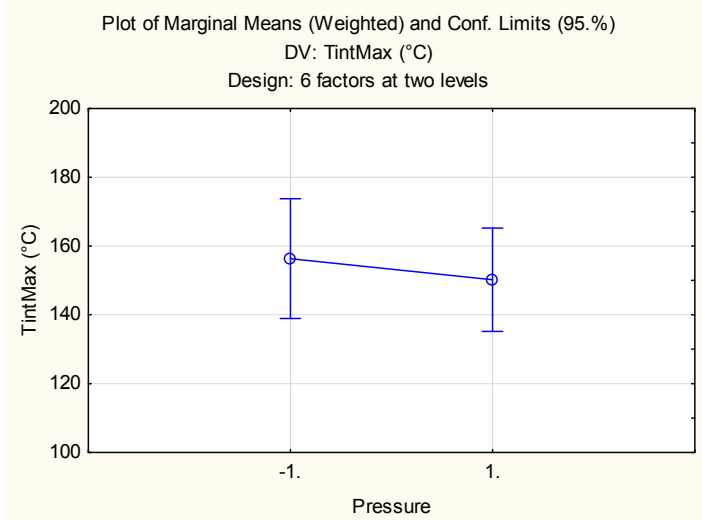

Figure 10. Average effect of pressure levels $(-1 \equiv 3$ bar; $1 \equiv 5$ bar) on TintMax according to Anova.

In the case of TintAvg, the same factors were significant, only with the inversion of the intermittence significance order with time, the latter having more significant influence in this case, as can be seen in Fig. 11. For the former, there was an average decrease of $11^{\circ} \mathrm{C}$ when increasing the heating percentage from $1 / 5$ to $1 / 3 \mathrm{~s}$. This value is similar to the $12{ }^{\circ} \mathrm{C}$ obtained for the influence of this intermittency factor in TintMax but lower than the $14{ }^{\circ} \mathrm{C}$ increase in TintAvg when increasing the total assay time. It is important to emphasize that, when observing the shape of the curves of the internal thermocouples in Fig. 12, the temperature starts low and stabilizes towards the end of the test. Thus, in more extended tests, a longer time is obtained at high temperatures, pulling the average temperature up more significantly.

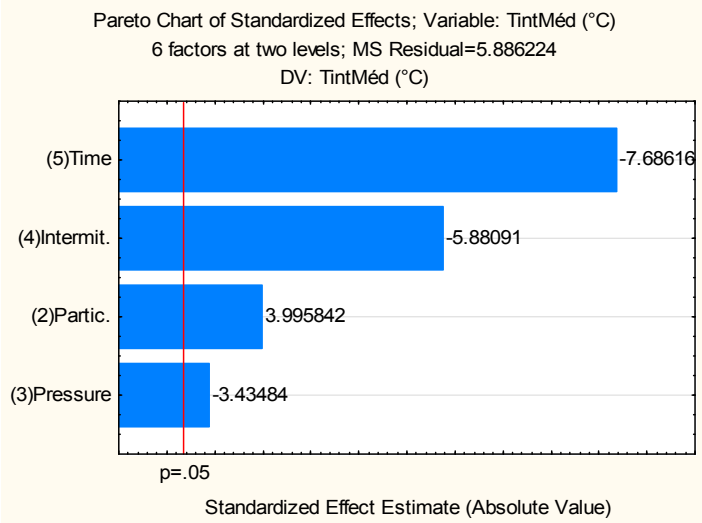

Figure 11. Pareto chart for significant input variables in TintAvg, according to Anova.

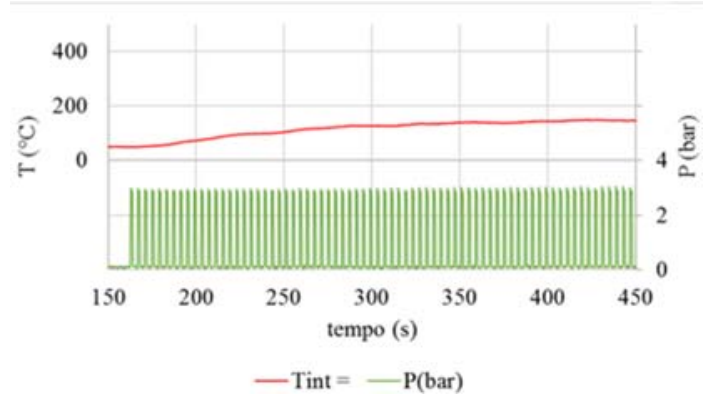

Figure 12. Tint variation over time as hot air heats the part and pulses of compressed air are released, as evidenced by the pressure spikes on the green curve.

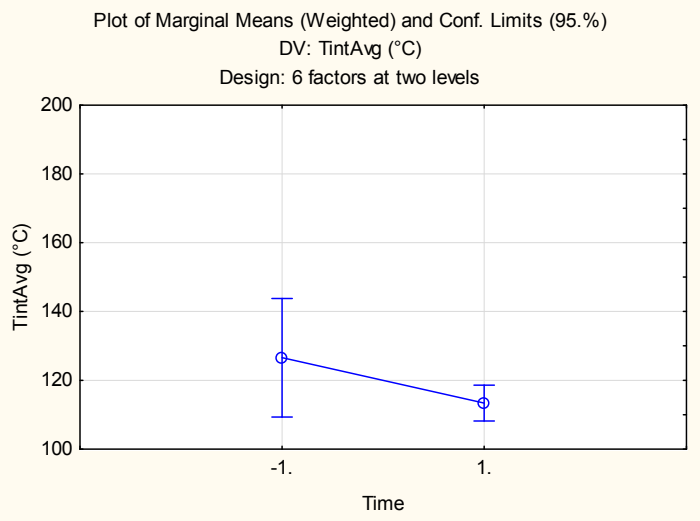

Figure 13. Average time effect $(-1 \equiv 7 \mathrm{~min} ; 1 \equiv 4 \min 40 \mathrm{~s})$ in TintAvg according to Anova. 
Particulate and pressure effects occur similarly for TintAvg, but to a lesser degree compared to TintMax. The first leads to an average increase of 6 ${ }^{\circ} \mathrm{C}$ in the average internal temperature using a mixture of ceramic particles with a lower volumetric flow. The second causes an average variation of only $5{ }^{\circ} \mathrm{C}$ when changing pressure levels. Likely, these more negligible effects in TintAvg are also due to the lower temperatures of the thermoplastic samples at the start of each test, which pull down all mean temperature values more severely than in the case of maximum temperatures.

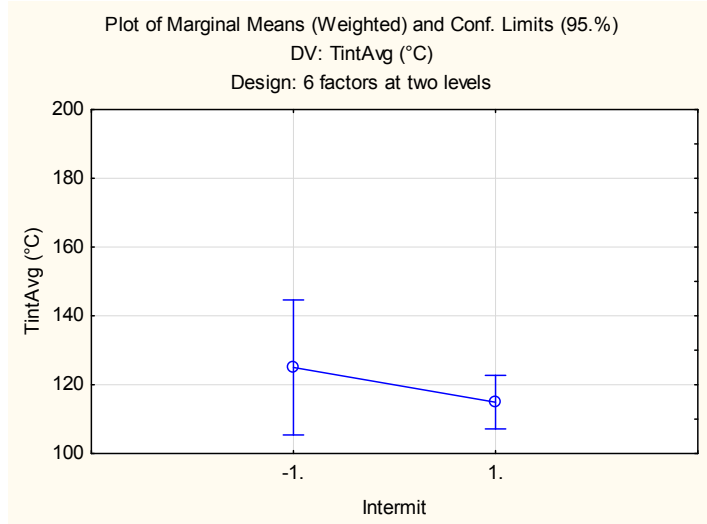

Figure 14. Average effect of intermittency levels ($1 \equiv 1 / 5 \mathrm{~s} ; 1 \equiv 1 / 3 \mathrm{~s}$ ) in TintAvg according to Anova.

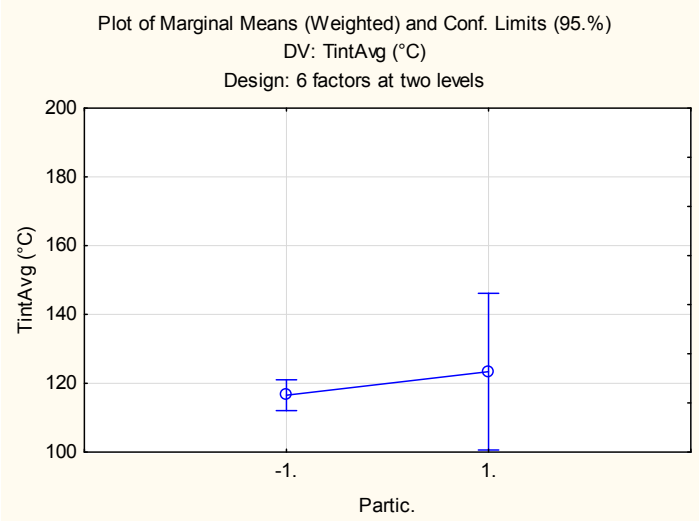

Figure 15 . Average particulate effect $(-1 \equiv 100 \%$ alumina; $1 \equiv 80 \%$ alumina $+20 \%$ titania) in TintAvg according to Anova.

Regarding the type of polymer and roughness, factors that are not significant for internal temperatures can be explained by the proximity of the internal surface thermocouples and the similarity of the roughness levels. First, although specific heats differ significantly, thermal conductivity is reasonably similar for polycarbonate and polyamide in the range of 100 to $150{ }^{\circ} \mathrm{C}$, as Osswald et al. (2006) show little affecting the temperature distribution for the short distance from the thermocouple to the surface. Second, as discussed in work by Campos et al. (2021), the difference in roughness was not enough to significantly modify the viscous friction of the polymer with hot air, which theoretically could change the numbers of $\mathrm{Re}, \mathrm{Pr}$, and $\mathrm{Nu}$, and consequently, the convection coefficient.

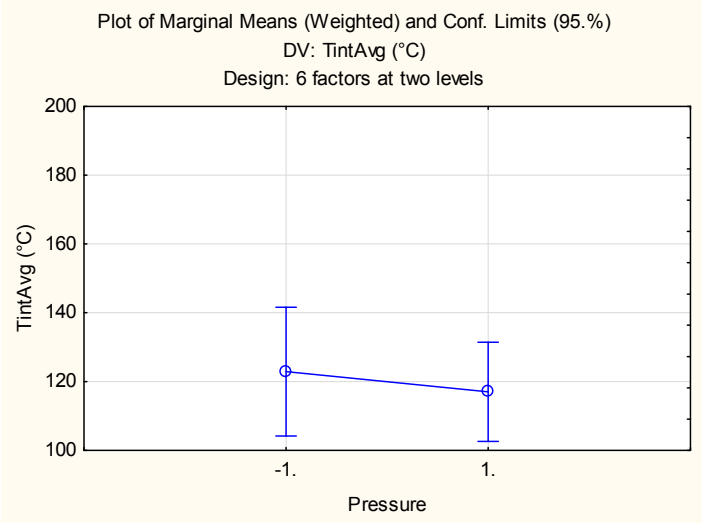

Figure 16. Average effect of pressure levels $(-1 \equiv 3$ bar; $1 \equiv 5$ bar) in TintAvg according to Anova.

\section{CONCLUSIONS}

The internal temperature of two thermoplastic polymers was measured by thermocouples coupled to an Arduino microcontroller to verify the influence of the processing conditions of polymers submitted to hot and cold air flows. Based on the methodology used, the following conclusions are possible:

- The Arduino-based measurement system is adequate for measuring internal temperatures in polymers, with sufficient sensitivity to capture variations according to process parameters.

- The maximum internal temperatures were around $153{ }^{\circ} \mathrm{C}$ for the conditions studied. In comparison, the averages were approximately $120{ }^{\circ} \mathrm{C}$, corresponding to, respectively, 31 and $24 \%$ of the maximum hot air temperature at the nozzle, and to 41 and $32 \%$ the temperature of the hot air upon reaching the surface of the parts.

- The low efficiency in heat transfer is typical of convection processes with hot air at low speed, is further accentuated by the low conductivity of the polymers.

- The most significant variation in internal temperatures was intermittence and time, with a more negligible effect for the particulate and compressed air pressure.

- The applied methodology provides reference values for unique thermoplastic manufacturing processes by blowing or other suitable techniques and can be used in the future for optimization and adaptive control of the process. 


\section{ACKNOWLEDGMENT}

The authors thank the CNPq and CAPES agencies for promoting research and the Heat, Mass, and Energy Transfer Laboratory at the Federal University of Uberlândia for their support of the experiments.

\section{REFERENCES}

Bahrami, M., 2021, "Engineering Thermodynamics and Heat Transfer," Laboratory for Alternative Engine Combustion. $<$ https://www.sfu.ca/ mbahrami/ensc388.html $>$. Acesso em 15/07/2021

Bergman, T. L., Incropera, F. P., DeWitt, D. P., \& Lavine, A. S., 2011, Fundamentals of heat and mass transfer. John Wiley $\&$ Sons, $7^{\text {th }}$ ed.

Campos, F. A. R., Okada, K. F. A., FerreiraOliveira, J. R., \& da Silva, L. R. R., 2021, "Temperature measurement of polymers under intermittent heating through use of thermocouple and arduino ${ }^{\circledR}$ microcontroller." Revista de Engenharia Térmica, Vol. 20, No. 1, p. 87-92.

Campos, F. A. R., Okada, K. F. Á., Oliveira, J. R. F., \& da Silva, L. R. R., 2020, "Quantification of uncertainty in temperature measurements with thermocouple and Arduino® compatible hardware." In Proceedings of the 18th Brazilian Congress of Thermal Sciences and Engineering-ENCIT2020.

Maxim Integrated, 2015, Cold-Junction Compensated Thermocouple-to-Digital Converter. Maxim Integrated, 5th ed.

Oliveira, J. R. F., de Lucena, L. R. R., dos Reis, R. P. B., de Araújo, C. J., Bezerra Filho, C. R., \& Arencibia, R. V. (2020). "Uncertainty quantification through use of the Monte Carlos method in a onedimensional heat conduction experiment." International Journal of Thermophysics, Vol. 41, No. 10, p. 1-19.

Omega Engineering, 2015, Manual de Referência Técnica de Temperatura. Omega Engineering

Osswald, T. A., Baur, E., Brinkmann, S., Oberbach, K. \& Schmachtenberg, E., 2006, International plastics handbook: the resource for plastics engineers. Hanser Publishers, Munich, 1st ed.

Vasconelos Neto, W., Soares, J. L. L., Martins, S. T. A. A., Oliveira, G. S. Q., Freire, W. A. C. \& Rocha, H. M. Z., 2018, Acquisition of thermocouple data by Arduino ${ }^{\circledR}$ microcontrollers. In Proceedings of the 17th Brazilian Congress of Thermal Sciences and Engineering-ENCIT 2018. Águas de Lindóia, Brazil.

Yunus A.. Çengel, \& Ghajar, A. J., 2020, Heat and Mass Transfer: Fundamentals and Applications. McGraw-Hill Education, $5^{\text {th }}$ ed. 